Grau, D., Abbaszadegan, A., and Assanair, R. (2019). "Process Versus Operations Workflow - Making the Case for Continuous Monitoring of Construction Operations." In: Proc. 27th Annual Conference of the International. Group for Lean Construction (IGLC), Pasquire C. and Hamzeh F.R. (ed.), Dublin, Ireland, pp. 563-572. DOI: https://doi.org/10.24928/2019/0197. Available at: 〈www.iglc.net>.

\title{
PROCESS VERSUS OPERATIONS WORKFLOW - MAKING THE CASE FOR CONTINUOUS MONITORING OF CONSTRUCTION OPERATIONS
}

\author{
David Grau', Amin Abbaszadegan², and Rizan Assanair ${ }^{3}$
}

\begin{abstract}
This article argues that an opportunity to leverage operations flow in construction exists. Operations flow represents the flow of work within a unit of production such as a worker or workstation. To date, construction has mostly neglected operations flow and solely focused on process flow. Process flow represents how the flow of work on a product moves through workstations or tasks. For example, the Last Planner System (LPS) exemplifies a successful approach to plan for tasks with resolved constraints, so that production units (e.g. crews) can flow smoothly through the built product or project. In order to spark a discussion in the construction community, this article provides a theoretical review of process and operations flow concepts and practices. In addition, interviews with subject matter experts in the automobile industry are leveraged in order to unveil how work and information flows are monitored in assembly lines. Based on the previous insights, a model for the continuous monitoring of operations in construction with the support of advanced technologies is discussed. The model is partially implemented in a healthcare project.
\end{abstract}

\section{KEYWORDS}

Project controls, variability, work flow, process flow, operations flow, value, takt-time planning.

\section{INTRODUCTION}

Flow stability is an indispensable characteristic of efficient and effective production (Sacks et al. 2010). In construction, however, the traditional focus of management has

1 David Grau, Assistant Professor, School of Sustainable Engineering and the Built Environment, Arizona State University, 660 S College Avenue, Tempe, AZ 85281, USA, Phone +1 (480) 727-0665; email: david.grau@asu.edu

2 Amin Abbaszadegan, Ph.D., School of Sustainable Engineering and the Built Environment, Arizona State University, 660 S College Avenue, Tempe, AZ 85281, USA, Phone +1 (416) 347-7547; email: aabbasz1@asu.edu

3 Rizwan Assainar, MS, School of Sustainable Engineering and the Built Environment, Arizona State University, 660 S College Avenue, Tempe, AZ 85281, USA, Phone +1 (480) 727-0665; email: ruizwan.assanair@asu.edu 
targeted the completed product or project outcome (Grau et al. 2014; Grau and Back 2015; Grau et al. 2016; Grau et al. 2017). Thus, management techniques were developed to target the conversion of outputs from inputs while neglecting the production process required to achieve those outputs (Howell and Ballard 1996, Koskela 2000). In doing so, the quality of work during execution or construction has been historically obviated (Kim and Ballard 2000; Seppänen 2009). For instance, the critical path method devises a project as the interrelation of tasks through start and finish type of relationships and thus simplistically assumes a constant flow of work through those tasks. Such project management focus fails to acknowledge other constraints with a likely impact on the flow of work (Koskela 2000). Indeed, multiple efforts have quantified the negative impact of workflow variability on craft labor productivity and project performance measures (Thomas 2000; Hamzeh 2009; Brodetskaia 2013; Seppänen 2009; Liu et al. 2011; Abbaszadegan and Grau 2015; Arashpour and Arashpour 2015).

Lean construction claims that efficient and effective production must satisfy the three fundamental axioms of transformation-flow-value (TFV) (Koskela 2000). The transformation of outputs based on inputs reflects the traditional management focus on the finished product (Olli Seppänen 2009). As previously explained, such transformational management focus has obviated the quality or flow of work during construction. The value aspect of production aims at optimizing the amount of value delivered to the final customer. For instance, the design and delivery of a high performing building in terms of energy consumption, maintenance, or functionality with a reduced cost is an example of high customer value. Finally, the flow aspect of production aims at the minimization of nonvalue added steps or the simplification of production with the overall objective to eradicate waste. The fluctuation or variability of workflow is an example of waste. An integral aspect of Toyota's total production approach is the maintenance of a smooth flow of product through assembly lines. In construction practice, the Last Planner System (LPS) (Ballard and Tommelein 2016; Ballard 2000) has become a mainstream planning and controls technique aiming at the improvement of workflow and minimization of variability and waste. LPS aims at the completion of lookahead and weekly work tasks as initially planned. In doing so, LPS assumes a constant workflow within each task and in-between them. At the end of the planned timeline (e.g. one week), the success of the plan is quantitatively assessed with the metric of percent plan complete (PPC). PPC quantifies the percentage of completed tasks over the total number of tasks that should have been completed. Since its development in the early 1990s, LPS has become a mainstream lookahead planning tool and has positively impacted construction. Yet, opportunities to improve production in construction exist.

Indeed, even though the tremendous success of LPS, opportunities for improvement are discussed in this paragraph. First, weekly work plans fail to support continuous learning and improvement. Despite PPC was conceived to support continuous improvement and learning, the reality is that, as Sacks (2010) pointed out, "the pressures of day-to-day construction make recording of success for learning (both within and beyond the current project) impractical." In reality, the causes for incomplete planned tasks are often not sought, recorded, or analyzed due to pressure and consequent lack of time. Second, the transfer of workflow in-between tasks or activities is still inefficient. According to PPC 
values, nearly $20 \%$ of planned tasks or activities are either not completed or, more frequently, not even started. This lack of completion of planned tasks indicates that the transfer of work between tasks fails at similar percentages. Third, controls is still a reactive endeavor and fails to address variability fluctuations as these happen. The assessment of planning success at the end of the week can only provide a past perspective on performed work and thus fails to resolve unexpected constraints on time. On the contrary, a proactive or immediate controls strategy could detect interruption or alterations of workflow as these happen and thus result in immediate mitigation actions. Indeed, Sacks et al. (2010) argue that a continuous or at least frequent flow of information and work status enables pull planning since such information enables work prioritization "in relation to signals from downstream demand." Finally, an opportunity to stabilize workflow through production units exists. Research and practice with a focus on workflow stabilization have targeted the smooth flow of work between tasks and activities but neglects the adverse effect of flow variability during those tasks (Sacks 2016). The stabilization of the pace of work in production units (e.g. crews) presents a latent opportunity to enhance the reliability of the planned work. Indeed, the maintenance of a stable pace of work eventually guarantees that each task will be completed on time and thus that the flow of work transfers to successor tasks as planned.

In response to such shortcomings, the study presented in this article details a theoretical technology-enabled monitoring model with the objective to stabilize workflow at production unit level, and leverage the accumulation of historical and fine-grained data to enhance the accuracy of planning and thus minimize discrepancies between expected and actual production rates.

\section{CONTROLLING VARIABILITY}

The reduction of variability and the stabilization of the flow of work has been a major cornerstone in production since the second half of the XX century. In manufacturing, Schonberger (1986) unambiguously states that "variability is the universal enemy." In construction, flow variability negatively impacts project performance measures (Thomas 2000; Hamzeh 2009; Arashpour and Arashpour 2015) and productivity (Brodetskaia 2013; Seppänen 2009; Liu et al. 2011). Previous research in construction based on simulation techniques provided further evidence of the negative impact of workflow fluctuations, as documented by Tommelein et al. (1999), Bashford et al. (2005), and Sacks and Golding (2007). Brodetskaia et al. (2013) have discussed a workflow management model for construction. Such model relies on three thrusts in order to ensure a smooth flow of work: design of a production system in consideration of the constraints that can cause fluctuations; proactive planning based on work-readiness and readiness of subsequent trades to accommodate work; and continuous reduction of variability during the production of individual activities. Complementarily, Koskela (2000) proposed 7 techniques for the design, control, and improvement of a production system in construction: minimization of non value-adding activities (waste); variability reduction; production time reduction; simplification; flexibility, and; transparency. Among them, the transparency and continuous control aspects towards the reduction of variability are of particular interest in 
this study since the communication of accurate and timely production information is essential for the stabilization of flow (Formoso et al. 2002; Rusell et al. 2009; Gurevich and Sacks 2014; Matthews et al. 2015). Information flow is critical for a smooth flow of work (Dave et al. 2010; Sacks et al. 2010).

As previously stated, LPS presupposes the stabilization of workflow between tasks or activities in lookahead or weekly work plans. LPS also transfers the accountability of the weekly work plan to those in charge of execution (i.e. last planners). During planning meetings, last planners collaboratively work to identify and resolve constraints (such as predecessor tasks or availability of space or other resources) before a commitment towards the execution of a task is made. At the end of the planned timeline (e.g. one week), PPC indicates the reliability of the proposed plan. Introduced late in the XX century, LPS represented a leap in the practice of construction with a focus on production systems design. Recently, LPS has been supported with advanced sensing and computing technologies (Sacks et al. 2010; Jongeling and Olofsson 2007; Gurevich and Sacks 2014; Matthews at al. 2015).

Actually, recent research and practice efforts have analyzed how advanced sensing, computing, and information technologies can support planning, execution, and controls. For instance, a 4D (3D model + schedule) approach resulted in the visual representation of line-of-balance execution progress in comparison to the planned work and enabled the visualization and analysis of actual vs. planned workflow (Jongeling and Olofsson 2007). Also, Building Information Modeling (BIM) tools were leverage to enable LPS and the communication of timely and accurate planning information among project team players (Sacks et al. 2010). The BIM+LPS approach enabled the visualization of the planned tasks in the object-oriented 3D model and ensured the consistency of schedule/planning changes by means of the automated propagation of such changes through the model. The influence of this approach on the work sequencing decisions by the last planners was determined (Gurevich and Sacks 2014). In order to alleviate the flow of production information that could alert of workflow variability, a theoretical model with commercial technologies was proposed by Matthews at al. (2015). The qualitative analysis of interviews from subject matter experts elicited the integration of project documents as a critical factor. Finally, a theoretical approach to integrate and visualize product and process information and extend it through the project life-cycle was recently proposed by Dave et al. (2016).

\section{PROCESS VS. OPERATIONS FLOW}

The flow of processes and the flow of operations coexist in any production system (Shingo and Dillon 1988). On the one hand, process flow represents how the flow of work on a product moves through workstations. Ideal production aims at meeting customer's demand rate with a steady process flow or takt time. On the other hand, operations flow represents the flow of work within a unit of production such as a worker or workstation. In this regard, the optimization of individual production units does not necessarily result in an optimal production system. For instance, an optimized operation unit may increase the rate of production and generate and out-of-sync demand from upstream operation units and supply to downstream operations units, and thus generate intermediate buffers and prevent takt- 
time production. In contrasts to manufacturing, Sacks (2016) observed in the construction literature a convoluted understanding of these two expressions of flow, even though Koskela (2000) and Koskela et al. (2007) had previously noted them. Sacks argues that such confusion results from the batch type of production in construction -as opposed to continuous production in manufacturing and assembly lines. In construction, the production units (such as crews) move through the built product at discrete intervals of time and result in a batch production mode. Despite these fundamental differences, as suggested by the later authors, this article maintains the semantics and thus refers to process workflow as the flow of work exerted on the building product by multiple production units (e.g. trades, crews) and to operations flow as the flow of work delivered by individual production units (at distinct work locations).

The different perception of flow between manufacturing/assembly and construction is mirrored in their control techniques. In manufacturing, monitoring focuses both on process and operation flows. For this discussion, the authors have interviewed subject matter experts in the automobile manufacturing industry in order to gain insights on their monitoring goals, practices, and techniques. The discussion on the rest of this paragraph is based on the analysis of such interviews. A real-time and continuous monitoring exists in order to detect and eradicate variability as it happens and at the source, and thus avoid the propagation of such variability into upstream and downstream operations. Thus, a worker in car assembly is not only empowered but also required to stop the line when the worker cannot finish the work within a marked stretch within the assembly line. Stopping the flow of production enables the elimination of variability right at the source and minimizes the unbalance of the entire assembly system. Such empowerment of the worker is a lean manufacturing strategy to respond in real-time and minimize the propagation of variability. In addition, such empowerment builds worker's accountability, such that the worker becomes an actor that must respond to variabilities in flow, quality, or other production issues. Such real-time communication of information also triggers management decisions. For instance, the late delivery of automobile parts in a just-in-time supply for an assembly line automatically activates contingency supply mechanisms. Thus, the continuous monitoring of the production system and its components results in a real-time flow of information that aims at the generation of corrective actions as soon as events occur.

In contrast, though, construction has invariably focused on process flow and neglected operations flow. LPS exemplifies a basic effort to plan tasks with a smooth flow of work between them. However, the reader should notice that while the planning focus in LPS is process flow, its weekly control informs on the reliability of the planned flow (i.e. PPC) after the weekly transformation cycle, i.e. from the perspective of the transformed work or output. This shortcoming is understandable since controls in shorter communication cycles could not have been realistically conceived with the state of technology in the early 2000s. As discussed in the previous section, recent studies have envisioned the support of advanced sensing, computing, and information technologies to address such shortcomings. However, these and other previous efforts have unequivocally focused on the planning and stabilization of process flow.

This lack of attention to operations flow in construction contrasts with the real-time monitoring of operations in lean manufacturing. Such contrast provides further motivation 
for the study presented in this article. Indeed, an opportunity exists to leverage advanced technologies for the exploration and stabilization of operations flow with a real-time feed of information. Within a production unit, fluctuations in workflow imply that resources are either underused or overused. Such fluctuations can eventually disrupt the smooth transfer of work in-between activities. The opportunity to stabilize operations flow is latent for finishing activities due to their short durations and multiple and varying dependencies on information, preceding tasks, and equipment, which cannot be guaranteed in advance (Brodetskaia et al. 2011).

\section{MODEL FOR THE CONTINUOUS MONITORING OF CONSTRUCTION OPERATIONS}

The model presented in this section builds on the previous theoretical insights and proposes the continuous monitoring of construction operations with the support of advanced technologies. Such fine-grained production data is accumulated into a historical database. Figure 1 illustrates the model. The fundamental idea is that fine-grained production records hold value and that such value can be leveraged to support estimating, planning, and execution based on the analysis of records from previously completed and similar projects. For example, precise execution work-hours can be populated by dividing the takeoff quantities extracted from the BIM model by previously recorded production rates in similar projects. Fine-grained production records can be leveraged to support additional project functions, such as pre-qualification of subcontractors based on past performance. Besides, such dataset could be mined in search for hidden patterns and correlations or correct predictions. Advanced sensing and computing technologies are envisioned in support of the data collection of fine-grained operations data in real- or near real-time. Similar to manufacturing, the analysis of real-time information can be leveraged to trigger corrective actions.

Indeed, the continuous monitoring aspect of the model was tested during the construction of a healthcare facility by a sophisticated contractor company. The reader can find the insights and results from the real-time collection of operations records and corrective actions in support of the healthcare project in Cruz-Rios et al. (2015) and Tang et al. (2014). The test actually combined the utilization of the proposed model in order to stabilize flow within operations with the Last Planner approach in order to ensure the flow of work between tasks. In regards to operations flow, the test proved that 1) sensing, mobile, and computing technologies enabled the collection of fine-grained operation records, and that 2) such continuous feed of fine-grained operations information enabled corrective actions that effectively stabilized workflow. Thus, test results proved the feasibility of the model and the potential to leverage operations workflow in order to stabilize production and reduce waste. The test also indicated that the continuous collection of vast amounts of labor productivity data should be resolved with the automation of the data gathering process. 


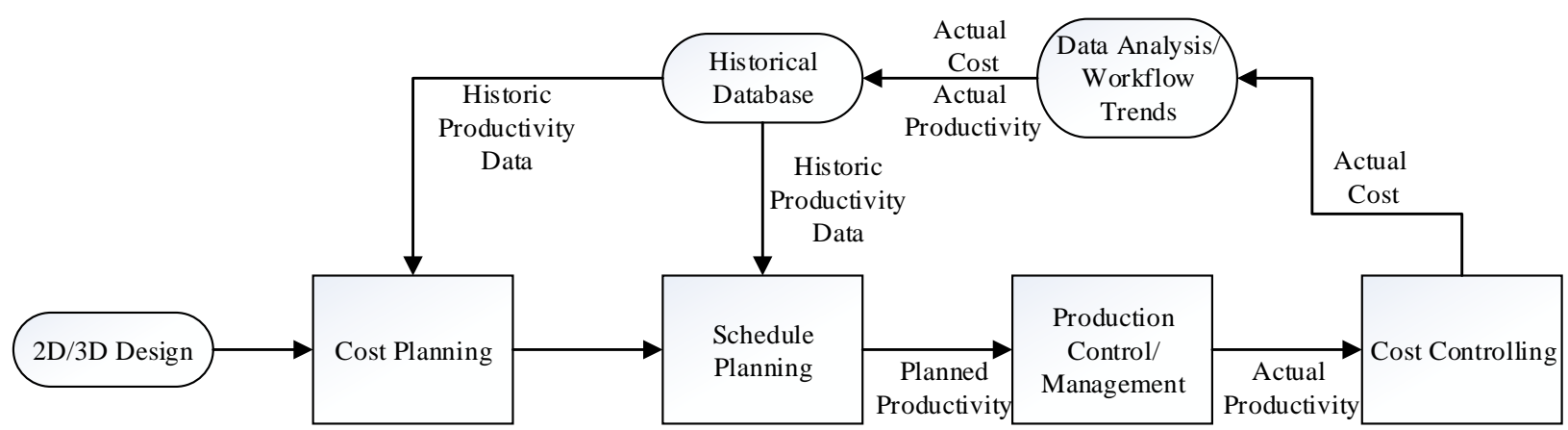

Figure 1. Continuous Monitoring Model

\section{CONCLUSIONS}

This article argues that an opportunity to leverage operations flow in construction exists. To date, construction has invariably focused on process flow and neglected operations flow. In reality, the construction literature shows a convoluted understanding of these two expressions of workflow. Such confusion likely results from the batch type of production in construction -as opposed to the continuous production in manufacturing and assembly lines.

For the purpose of this study, the authors interviewed subject matter experts in the automobile manufacturing industry in order to gain insights on the controls of an assembly line. The analysis of the interviews unveiled how car makers leverage the real-time control of the assembly line for the stabilization of workflow and reduction of variability.

Based on such insights, a model for the continuous monitoring of operations in construction with the support of advanced technologies was detailed. The fundamental idea is that fine-grained production records hold value and that such value can be leveraged to support estimating, planning, and execution based on the analysis of records from previously completed and similar projects. As proof of concept, the continuous monitoring aspect of the model was tested during the construction of a healthcare facility by a sophisticated contractor company. Test results proved the feasibility of the model and the potential to leverage operations workflow in order to stabilize production and reduce waste. Further studies should investigate the stabilization of operations and process flows for effective production management.

\section{REFERENCES}

Abbaszadegan, A., and Grau, D. (2015). "Impact of Real-Time Project Control on Capital Cost and Schedule Performance." University of Zagreb, Organization, Technology \& Management In Construction: An International Journal, 7(2), pp. 1289-1294.

Arashpour, M., \& Arashpour, M. (2015). "Analysis of Workflow Variability and Its Impacts on Productivity and Performance in Construction of Multistory Buildings.” ASCE, Journal of Management in Engineering, 31(6), 04015006. 
Grau, D., and Back, W.E. (2015). "Predictability Index - A Novel Metric to Assess Cost and Schedule Performance." ASCE, Journal of Construction Engineering and Management, 04015043-1 to -8.

Grau, D., Back, E., Abbaszadegan, A., and Sirven, R. (2014). "The Predictability Index A Novel Project Performance Metric to Assess the Early Prediction of Cost and Time Outcomes." Conference Proceedings, Construction Research Congress 2014, pp. 2306-2314, Atlanta, GA, May 19 - 21, 2014.

Grau, D., Back, W.E., and Aguilar, G.M. (2017). "Organizational Behavior Influence on Predictability." ASCE, Journal of Management in Engineering, 33(5), pp. 04017027-1 to -8 .

Grau, D., Back, W.E., and Hossain, N. (2016). "Influence of Risk and Change Events on Cost, Schedule, and Predictability Performances." ASCE, Journal of Professional Issues in Engineering Education and Practice, 04016006-1 to -9.

Ballard, G. (2000). The Last Planner System of Production Control. PhD Thesis. The University of Birmingham, Birmingham, UK.

Ballard, G. and Tommelein, I.T. (2016). Current Process Benchmark for the Last Planner System, Project Production Systems, University of California, Berkeley, CA.

Bashford, H.H., Walsh, K., and Sawhney, A. (2005). "Production system loading-cycle time relationship in residential construction." ASCE, Journal of Construction Engineering and Management, 131 (1), 15-22.

Brodetskaia, I., Sacks, R., \& Shapira, A. (2013). Stabilizing Production Flow of Interior and Finishing Works with Reentrant Flow in Building Construction. ASCE, Journal of Construction Engineering and Management, 139(6), 665-674.

Brodetskaia, I., Sacks, R., and Shapira, A. (2011). "A workflow model for finishing works in building construction." Taylor and Francis, Construction Management and Economics, 29(12), 1209-1227

Cruz-Rios, F., Grau, D., Rizwan, A., Ganapathy, R., and Diosdado, J. (2015). "Stabilizing Craft Labor Workflow with Instantaneous Progress Reporting." In: Seppänen, O., González, V.A. \& Arroyo, P., 23rd Annual Conference of the International Group for Lean Construction, pp. 43-52. Perth, Australia, July 29-31, 2015.

Dave, B., Kubler, S., Främling, K. \& Koskela, L. (2016). "Opportunities for enhanced lean construction management using Internet of Things standards." Elsevier, Automation in Construction, 61(C), 86-97.

Flyvbjerg,B. (2006). "From Nobel Prize to Project Management: Getting Risks Right." Project Management Journal, 37 (3), pp. 5-15.

Formoso, C.T, Santos, A.D., and Powell, J.A. (2002). "An Exploratory Study On The Applicability Of Process Transparency In Construction Sites.” Journal of Construction Research, 3 (1), 35-54.

Gurevich, U., \& Sacks, R. (2014). "Examination of the effects of a KanBIM production control system on subcontractors' task selections in interior works." Elsevier, Automation in Construction, 37, 81-87.

Hamzeh, F. (2009). "Improving Construction Workflow - The Role of Production Planning and Control." Civil Engineering, UC Berkeley, CA. 
Howell, G., and Ballard, G. (1996). "Can project controls do its job?.” IGLC Proceedings, 4th Annual Conference of the International Group for Lean Construction, 1996.

Jongeling, R., and Olofsson, T. (2007). "A method for planning of work-flow by combined use of location-based scheduling and 4D CAD." Elsevier, Automation in Construction, 16(2), 189-198.

Kim, Y.W. and Ballard, G. (2000) "Is the earned-value method an enemy of work-flow?." In Ballard, G. and Chua, D. (eds.) GLC Proceedings, 9th Annual Conference of the International Group for Lean Construction, Singapore, 2000.

Koskela, L. (1992). "Application of the new production philosophy to construction." Technical. Rep. No. 72, Center for Integrated Facility Eng., Dept. of Civil Eng., Stanford University, Stanford, CA.

Koskela, L. (2000). "An exploration towards a production theory and its application to construction.” D. Tech, Helsinki University of Technology, Espoo.

Liker, J.E. (2003). “The Toyota Way.” McGraw-Hill, New York, 2003.

Matthews, J., Love, P.E.D., Heinemann, S., Chandler, R., Rumsey, C., and Olatunj, O. (2015). "Real-time progress management: Re-engineering processes for cloud-based BIM in construction." Elsevier, Automation in Construction, 58(C), 38-47.

Liu, M., Ballard, G., Ibbs, W. (2011). "Work Flow Variation and Labor Productivity: Case Study." ASCE, Journal of Management in Engineering, 27(4), 236-242.

Mulva, S.P. and Dai, J. (2012). "Performance assessment." Construction Industry Institute, Austin, TX.

Russell, A.D., Chiu, C.Y., and Korde, T. (2009). "Visual representation ofconstruction management data." Elsevier, Automation in Construction, 18 (8), 1045-1062.

Sacks, R., \& Goldin, M. (2007). "Lean Management Model for Construction of High-Rise Apartment Buildings." ASCE, Journal of Construction Engineering and Management, 133(5), 374-384.

Sacks, R. (2016). "What constitutes good production flow in construction? Construction Management and Economics." Taylor and Francis, Construction Management and Economics, 34(9), 641-656.

Sacks, R., Radosavljevic, M. and Barak, R. (2010). "Requirements for building information modeling based lean production management systems for construction." Elsevier, Automation in Construction, 19, 641-55.

Seppänen, O. (2009). "Empirical research on the success of production control in building construction projects." Ph.D., Helsinki University of Technology, Espoo, Finland.

Shingo, S. and Dillon, A.P. (1989). "A study of the Toyota production system: from an industrial engineering viewpoint (Produce What is Needed, When it's Needed)." Taylor \& Francis, New York, NY.

Tang, P., Grau, D., Ganapathy, R., Diosdado, J., and Abbaszadegan, A. (2014). "Workflow Stabilization with Fine-Grained Work Packaging and Near Real-Time Progress Monitoring." Proceedings from $22^{\text {nd }}$ Annual Conference, International Group for Lean Construction, pp. 739-750, Oslo, Norway, June 25 - 27, 2014.

Thomas, H. (2000). "Schedule Acceleration, Work Flow, and Labor Productivity." ASCE, Journal of Construction Engineering and Management, 126(4), 261-267. 
Grau, D., Abbaszadegan, A., and Assanair, $R$

Tommelein, I.D., Riley, D.R., Howell, G.A. (1999). "Parade game: impact of workflow variability on trade performance." ASCE, Journal of Construction Engineering and Management, 125 (5), 304-310.

Wong, J., Wang, X. Li, H., Chan, G., and Li, H. (2014). "A review of cloud-based BIM technology in the construction sector." Journal of Information Technology and Construction, 19, 281-291. 